\title{
Fenofibrate inhibits adipocyte hypertrophy and insulin resistance by activating adipose PPAR $\alpha$ in high fat diet-induced obese mice
}

\author{
Sunhyo Jeong and Michung Yoon ${ }^{1}$
}

\author{
Department of Life Sciences \\ Mokwon University \\ Daejeon 302-729, Korea \\ ${ }^{1}$ Corresponding author: Tel, 82-42-829-7585; \\ Fax, 82-42-829-7580; E-mail, yoon60@ @mokwon.ac.kr \\ DOI 10.3858/emm.2009.41.6.045
}

Accepted 14 January 2009

Abbreviations: ACOX, acyl-COA oxidase; FF, fenofibrate; H\&E, hematoxylin and eosin; HD, enoyl-CoA hydratase/3-hydroxyacylCoA dehydrogenase; MCAD, medium chain acyl-CoA dehydrogenase; PPAR $\alpha$, peroxisome proliferator-activated receptor $\alpha$; R.D.U., relative density units

\begin{abstract}
Peroxisome proliferator-activated receptor $\alpha$ (PPAR $\alpha)$ activation in rodents is thought to improve insulin sensitivity by decreasing ectopic lipids in non-adipose tissues. Fenofibrate, a lipid-modifying agent that acts as a PPAR $\alpha$ agonist, may prevent adipocyte hypertrophy and insulin resistance by increasing intracellular lipolysis from adipose tissue. Consistent with this hypothesis, fenofibrate decreased visceral fat mass and adipocyte size in high fat diet-fed obese mice, and concomitantly increased the expression of PPAR $\alpha$ target genes involved in fatty acid $\beta$-oxidation in both epididymal adipose tissue and differentiated 3T3-L1 adipocytes. However, mRNA levels of adipose marker genes, such as leptin and TNF $\alpha$, were decreased in epididymal adipose tissue by fenofibrate treatment. Fenofibrate not only reduced circulating levels of free fatty acids and triglycerides, but also normalized hyperinsulinemia and hyperglycemia in obese mice. Blood glucose levels of fenofibrate-treated mice were significantly reduced during intraperitoneal glucose tolerance test compared with obese controls. These results suggest that fenofibrate-induced fatty acid $\beta$-oxidation in visceral adipose tissue may be one of the major factors leading to decreased adipocyte size and improved insulin sensitivity.
\end{abstract}

Keywords: adipocytes; hyperglycemia; hyperlipide- mia; insulin resistance; PPAR $\alpha$

\section{Introduction}

Insulin resistance is most closely associated with visceral obesity (Kissebah, 1997; Jensen, 2006). Evidence from human and animal studies indicates that obesity due to adipocyte hypertrophy results in insulin resistance and diabetes, whereas restoration of normal adipose tissue levels alleviates the insulin resistance present in obesity (Spiegelman and Flier, 1996; Murphy et al., 1997; Wickelgren, 1998; Brunzell and Hokanson, 1999). Hypertrophic adipocytes increase TNF $\alpha$, leptin, and circulating free fatty acids, which have been implicated in the development of insulin resistance (Hotamisligil et al., 1993; Taylor et al., 1996; Boden, 1997; Okuno et al., 1998). Thus, the conversion of hypertrophic adipocytes into small adipocytes appears to play an important role in the alleviation of both insulin resistance and diabetes (Okuno et al., 1998; de Souza et al., 2001).

Fibrates act as nuclear peroxisome proliferatoractivated receptor $\alpha(P P A R \alpha)$ agonists that regulate the expression of genes critical for lipid and lipoprotein metabolism (Schoonjans et al., 1996; Staels et al., 1998; Kliewer et al., 1999). Fibrates have been shown to regulate obesity in rodents by increasing hepatic fatty acid oxidation and decreasing the levels of circulating triglycerides responsible for adipose cell hypertrophy and hyperplasia (Yoon et al., 2002, 2003; Jeong et al., 2004a, b), suggesting that PPAR $\alpha$ is involved in the control of insulin resistance caused by obesity. However, studies have shown that improvement of insulin signaling by PPAR $\alpha$ activation is due largely to a decrease of ectopic lipids in non-adipose tissue.

Although PPAR $\alpha$ plays an important role in fatty acid oxidation in liver and skeletal muscle, it is reported that PPAR $\alpha$ activators may affect adipose tissue metabolism. For example, administration of bezafibrate, a typical PPAR activator, leads to dedifferentiation of adipocytes into preadipocyte-like cells through the activation of genes involved in both mitochondrial and peroxisomal $\beta$-oxidation (Cabrero et al., 2001; Vázquez et al., 2001); the PPAR $\alpha$ ligand GI259578A decreases the mean size of adipocytes in white adipose tissue (Okamoto 
et al., 2007). Accordingly, we hypothesize that adipose PPAR $\alpha$ activation by fenofibrate may inhibit adipocyte hypertrophy, resulting in amelioration of insulin resistance.

Therefore, the objectives of the present study were 1) to determine whether fenofibrate activates adipose expression of PPAR $\alpha$ target genes involved in fatty acid $\beta$-oxidation and 2 ) to examine the subsequent effects of fenofibrate on adipocyte size and insulin sensitivity. Our data demonstrated that fenofibrate treatment increased mRNA expression of enzymes responsible for fatty acid $\beta$-oxidation in visceral adipose tissue, leading to a reduction in

\section{A}

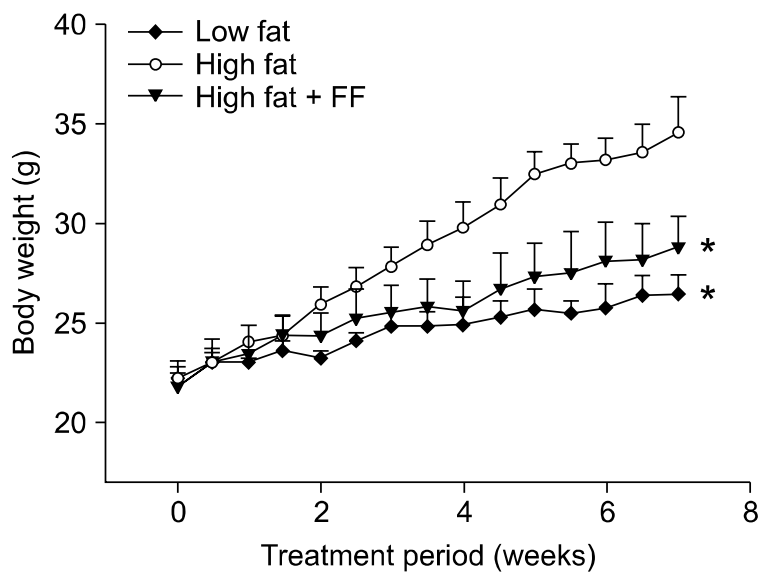

B

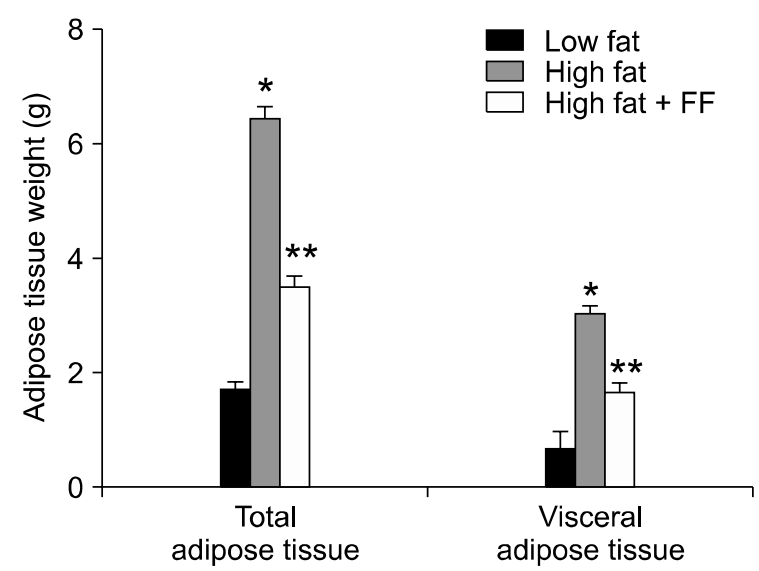

Figure 1. Body weight and adipose tissue mass after fenofibrate treatment. Adult male mice received a low fat, high fat, or fenofibrate-supplemented (FF; $0.05 \% \mathrm{w} / \mathrm{w}$ ) high fat diet for seven weeks. All values are expressed as the mean \pm SD. (A) Body weights at the end of the treatment period are significantly different when comparing the high fat group to the low fat or high fat plus FF $(P<0.05)$ groups. (B) Total and visceral adipose tissues were measured at the end of the study. ${ }^{*} \mathrm{P}<0.05$ compared with low fat group, ${ }^{* *} P<0.05$ compared with high fat group. adipocyte size and the alleviation of insulin resistance.

\section{Results}

\section{Regulation of body weight, visceral fat mass, and adipocyte size by fenofibrate}

Fenofibrate treatment prevented the high fat diet-induced increase in body weight (Figure 1A). Both total and visceral adipose tissue weights were also decreased in mice given a high fat diet supplemented with fenofibrate as compared to mice fed the high fat diet (Figure 1B). Histological analysis showed that fenofibrate caused a $43 \%$ decrease in the size of adipocytes in epididymal adipose tissue in the fenofibrate-enriched, high fat diet-fed mice versus mice fed the high fat diet (Figure 2A). The average size of adipocytes in the high fat diet-fed obese mice was 5,505 $\pm 354 \mu \mathrm{m}^{2}$, whereas adipocyte size was $3,135 \pm 182 \mu \mathrm{m}^{2}$ in fenofibrate-treated obese mice (Figure 2B). The number of adipocytes in a fixed area was increased by $75 \%$ in fenofibrate-treated obese mice compared with high fat diet fed-obese mice (Figure $2 \mathrm{C}$ ), suggesting that fenofibrate caused an increase in small adipocytes and a decrease in large adipocytes in epididymal adipose tissue of obese mice. With respect to the physiological significance of such changes, molecules that either are generated or secreted by hypertrophic adipocytes have been implicated in the development of insulin resistance (Hotamisligil et al., 1993; Taylor et al., 1996). Thus, fenofibrate may alleviate insulin resistance, at least in part, due to its ability to reduce adipocyte size.

\section{Expression of PPAR $\alpha$ target genes involved in fatty acid $\beta$-oxidation in visceral adipose tissue and differentiated 3T3-L1 adipocytes}

To determine whether the reduction of adipocyte size can be induced by fenofibrate-mediated PPAR $\alpha$ actions in adipose tissue, we measured the mRNA levels of PPAR $\alpha$ target enzymes responsible for peroxisomal and mitochondrial fatty acid $\beta$-oxidation in visceral adipose tissue of obese mice and mouse adipocyte cultures. The fenofibratetreated, high fat diet-fed mice exhibited substantially higher mRNA levels of enzymes for fatty acid $\beta$-oxidation in epididymal adipose tissue [e.g., acyl-CoA oxidase (ACOX), enoyl-CoA hydratase/3hydroxyacyl-CoA dehydrogenase (HD), and medium chain acyl-CoA dehydrogenase (MCAD) by $186 \%$, $145 \%$, and $20 \%$, respectively] compared with high fat diet-fed mice (Figure 3). Similarly, treatment 
A
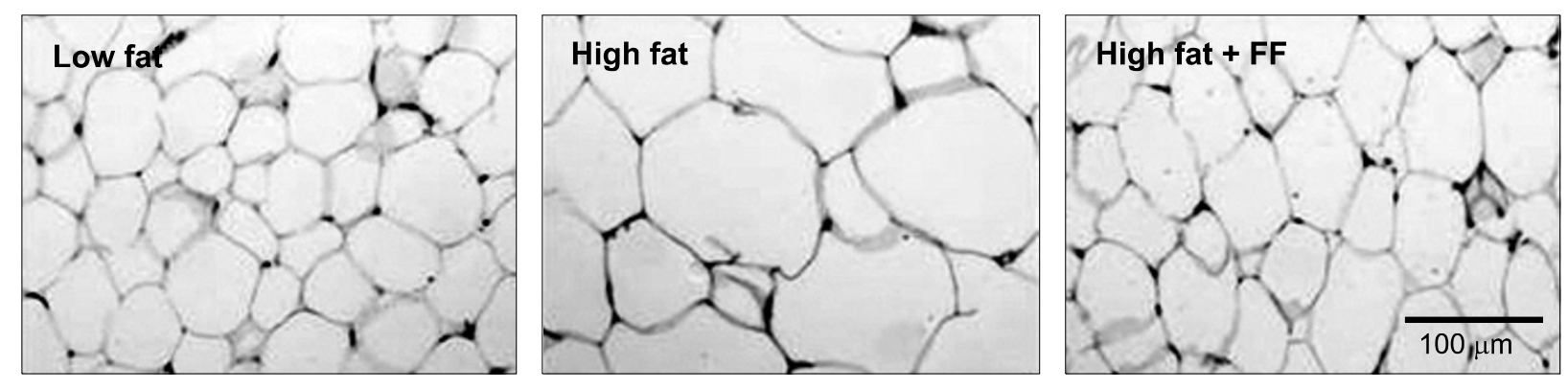

B

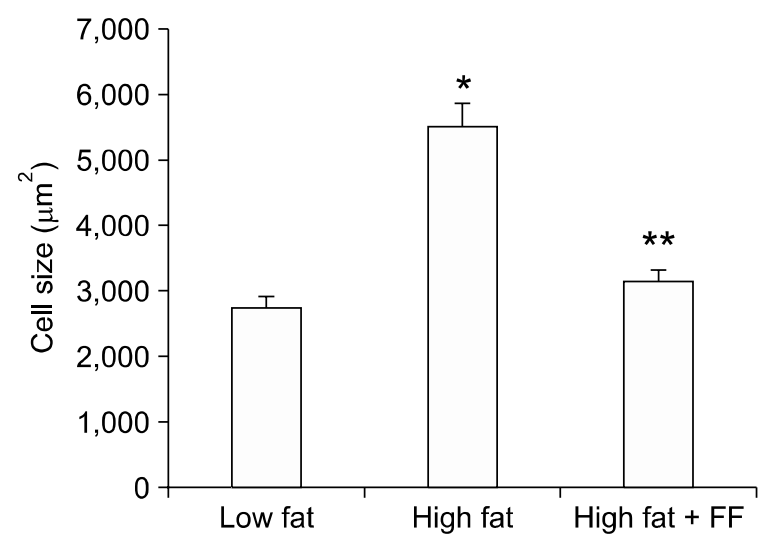

C

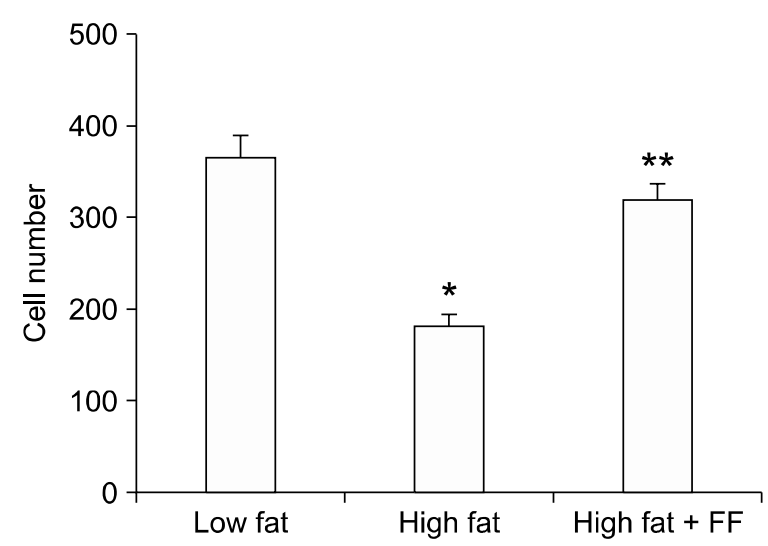

Figure 2. Histology of epididymal white adipose tissue. Adult male mice received a low fat, high fat, or fenofibrate-supplemented (FF; $0.05 \%$ w/w) high fat diet for seven weeks. (A) Representative hematoxylin and eosin-stained sections ( $5 \mu \mathrm{m}$ thick) of epididymal adipose tissue. Adipocyte size from high fat plus FF groups was smaller than that from high fat groups. The size (B) and number (C) of adipocytes in a fixed area $\left(1,000,000 \mu \mathrm{m}^{2}\right)$ were measured. All values are expressed as the mean $\pm \mathrm{SD}$. ${ }^{*} P<0.05$ compared with low fat group, ${ }^{* *} P<0.05$ compared with high fat group.

with the potent PPAR $\alpha$ ligand, Wy14,643, increased mRNA expression of ACOX, HD, and MCAD by $50 \%, 18 \%$, and $11 \%$, respectively, in differentiated 3T3-L1 cells (Figure 4). These results suggest that fenofibrate may decrease adipocyte size, in part, through adipose PPAR $\alpha$ activation.

\section{Expression of adipose marker genes}

Since obese, insulin-resistant rodents with hyper- trophic adipocytes are known to overexpress adipocyte marker genes, such as PPAR $\gamma$, adipocyte fatty acid-binding protein, leptin, and TNF $\alpha$ (Brun et al., 1997; Okuno et al., 1998), we tested the effects of fenofibrate on expression of leptin and TNF $\alpha$ mRNA in epididymal adipose tissue. Consistent with the effects of fenofibrate on adipocyte size, fenofibrate treatment significantly decreased leptin and TNF $\alpha$ mRNA levels by $19 \%$ and $26 \%$, respectively, compared to those in the group that

Table 1. Circulating levels of free fatty acids, triglycerides, insulin, and glucose after fenofibrate treatment.

\begin{tabular}{lcccc}
\hline \multicolumn{1}{c}{ Group } & Free fatty acids (Eq/L) & Triglycerides $(\mathrm{mg} / \mathrm{dl})$ & Insulin $(\mathrm{ng} / \mathrm{ml})$ & Glucose $(\mathrm{mg} / \mathrm{dl})$ \\
\hline Low fat & $1,318 \pm 59$ & $60 \pm 9$ & $0.12 \pm 0.014$ & $203 \pm 19$ \\
High fat & $1,629 \pm 83^{*}$ & $118 \pm 6^{*}$ & $0.26 \pm 0.027^{*}$ & $361 \pm 29^{*}$ \\
High fat + FF & $1,421 \pm 50^{* *}$ & $77 \pm 2^{* *}$ & $0.11 \pm 0.008^{* *}$ & $210 \pm 26^{* *}$ \\
\hline
\end{tabular}

Adult male mice received a low fat, high fat, or fenofibrate-supplemented (FF; $0.05 \% \mathrm{w} / \mathrm{w}$ ) high fat diet for 7 weeks. All values are expressed as the mean \pm SD. ${ }^{*} P<0.05$ compared with low fat group, ${ }^{* *} P<0.05$ compared with high fat group. 
A

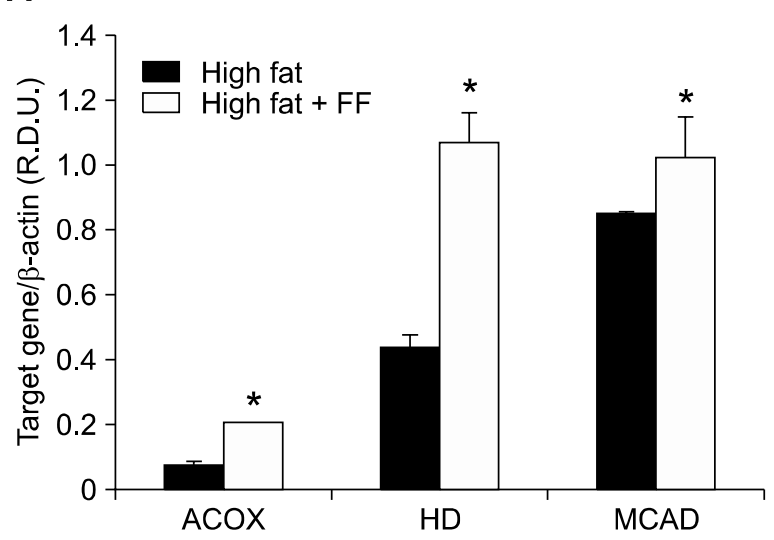

B

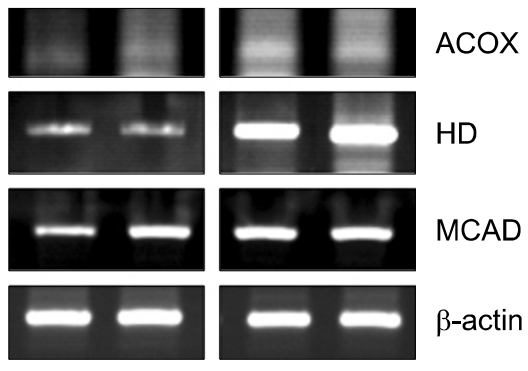

High fat High fat + FF

Figure 3. The mRNA expression levels of PPAR $\alpha$ target genes in visceral adipose tissue of obese mice. (A) The relative mRNA expression of PPAR $\alpha$ target enzymes was measured in obese mice after fenofibrate treatment. RNA was extracted from epididymal adipose tissue, and mRNA levels of PPAR $\alpha$ target enzymes and $\beta$-actin were measured as described in the Methods. All values are expressed as the mean \pm SD of R.D.U. (relative density units) using $\beta$-actin as a reference. ${ }^{*} P<0.05$ compared with high fat group. (B) Representative PCR bands from one of three independent experiments are shown. ACOX, acyl-CoA oxidase; HD, enoyl-CoA hydratase/3-hydroxyacyl-CoA dehydrogenase; MCAD, medium chain acyl-CoA dehydrogenase.

was fed a high fat diet only (Figure 5).

\section{Circulating levels of lipids, glucose, and insulin}

Serum free fatty acid and triglyceride levels were higher by $24 \%$ and $91 \%$, respectively, in the high fat diet group compared with the low fat diet control group (Table 1). However, serum free fatty acid levels decreased by $12 \%$, and plasma triglycerides levels decreased by $35 \%$ in fenofibrate-treated mice compared with those in high fat diet-fed mice.
Fenofibrate also caused a decrease in both plasma insulin and glucose levels by $58 \%$ and $42 \%$, respectively, in high fat diet-fed animals, thus improving insulin resistance in obese mice.

\section{Intraperitoneal glucose tolerance test}

The effects of fenofibrate on changes in blood glucose levels were measured during intraperitoneal glucose tolerance test in high fat diet-fed mice. After seven weeks of treatment with fenofi-
A

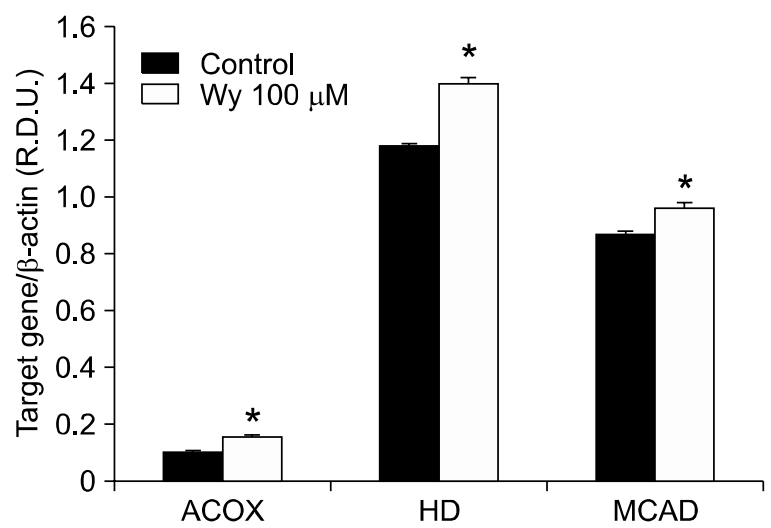

B
Control

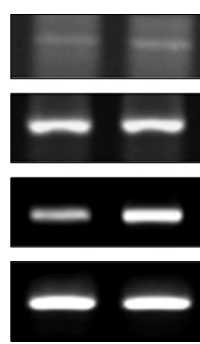

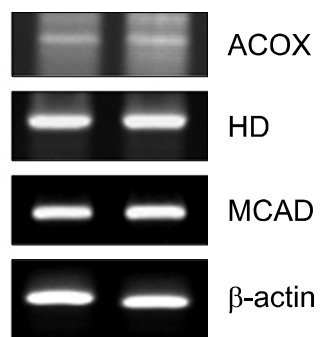

Wy $100 \mu \mathrm{M}$

Figure 4. The mRNA expression levels of PPAR $\alpha$ target genes in differentiated 3T3-L1 adipocytes. (A) The relative mRNA expression of PPAR $\alpha$ target enzymes was measured in differentiated 3T3-L1 adipocytes after Wy14,643 (Wy) treatment. RNA was extracted from differentiated 3T3-L1 adipocytes, and mRNA levels of PPAR $\alpha$ target enzymes and $\beta$-actin were measured as described in Methods. All values are expressed as the mean \pm SD of R.D.U. (relative density units) using $\beta$-actin as a reference. ${ }^{*} P<0.05$ compared with control group. (B) Representative PCR bands from one of three independent experiments are shown. ACOX, acyl-CoA oxidase; HD, enoyl-CoA hydratase/3-hydroxyacyl-CoA dehydrogenase; MCAD, medium chain acyl-CoA dehydrogenase. 
A

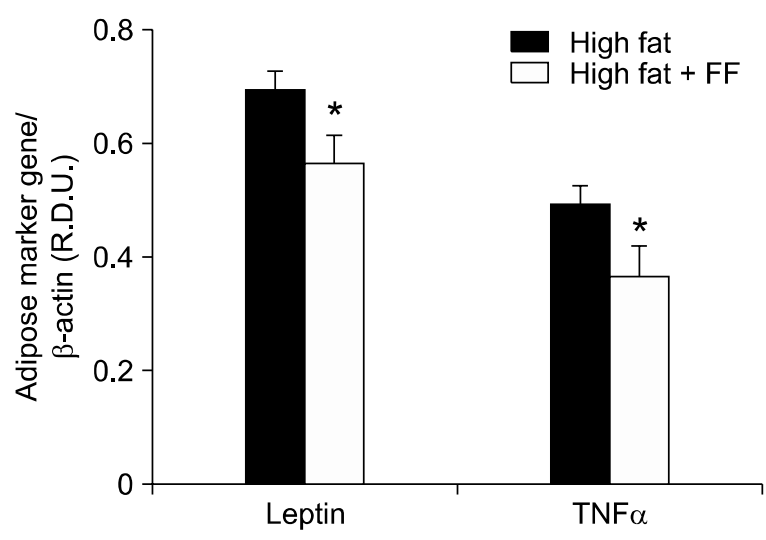

B

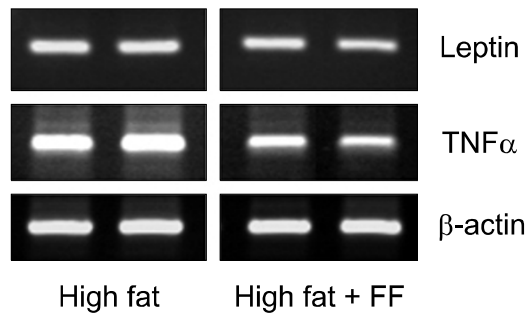

Figure 5. The mRNA expression levels of adipocyte marker genes in visceral adipose tissue of obese mice. (A) Adult male mice received a high fat diet or fenofibrate-supplemented (FF; $0.05 \% \mathrm{w} / \mathrm{w}$ ) high fat diet for seven weeks. RNA was extracted from epididymal adipose tissue and mRNA levels of leptin, TNF $\alpha$, and $\beta$-actin were measured as described in the Methods. All values are expressed as the mean \pm SD of R.D.U. (relative density units) using $\beta$-actin as a reference. (B) Representative PCR bands from one of three independent experiments are shown. ${ }^{*} P<0.05$ compared with high fat group.

brate, mice exhibited significant reductions in blood glucose concentrations following intraperitoneal glucose administration compared with obese control mice (Figure 6). These results indicate that fenofibrate may improve glucose tolerance in mice with diet-induced obesity.

\section{Discussion}

Our results demonstrated that fenofibrate decreased adipocyte size as well as body weight and visceral adipose tissue mass in high fat dietinduced obese mice. Body weight and visceral fat

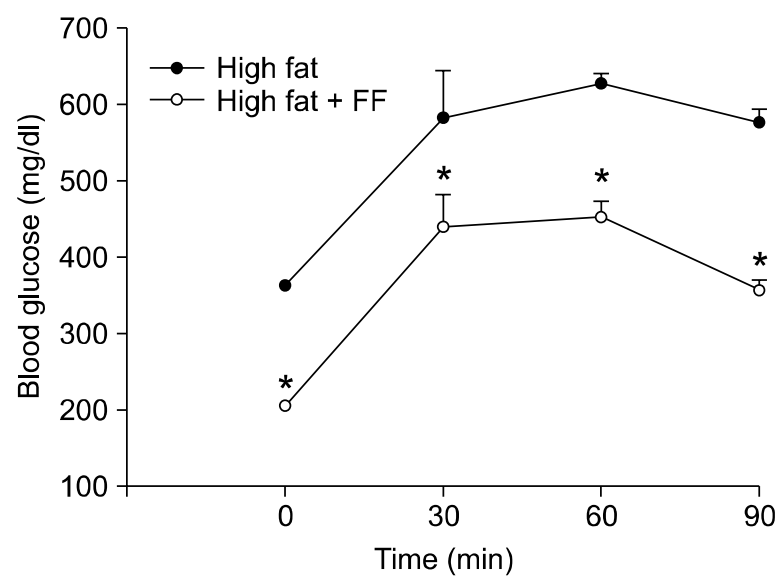

Figure 6. Changes in blood glucose levels during intraperitoneal glucose tolerance test. Adult male mice received a high fat diet or fenofibrate-supplemented (FF; $0.05 \%$ w/w) high fat diet for seven weeks. After a twelve-hour fast, mice intraperitoneally received glucose $(2 \mathrm{~g} / \mathrm{kg}$ body weight). All values are expressed as the mean $\pm \mathrm{SD}$. ${ }^{*} P<0.05 \mathrm{com}-$ pared with high fat group. mass were decreased significantly by fenofibrate treatment, although these properties did not reach the levels observed in low fat diet-fed mice. In addition to the effects of fenofibrate on visceral fat mass, histological examination of epididymal adipose tissue revealed that fenofibrate greatly decreased the average size of adipocytes in high fat dietinduced obese mice. Adipocyte size in epididymal adipose tissue was $43 \%$ lower in fenofibratecontaining high fat diet-fed mice compared with adipocyte size in high fat diet-fed mice. Our results also showed that fenofibrate increased the number of small adipocytes, while decreasing the number of large adipocytes in a fixed area, suggesting that fenofibrate induced the conversion of large adipocytes into smaller adipocytes. Since visceral obesity due to adipocyte hypertrophy is closely associated with various metabolic syndromes, including insulin resistance (Flier, 2004; Wellen and Hotamisligil, 2005), and large adipocytes are associated with insulin resistance, whereas smaller adipocytes are associated with insulin sensitivity (Okuno et al., 1998; Kubota et al., 1999; Kadowaki, 2000 ), it is likely that fenofibrate may control insulin sensitivity due to its ability to inhibit adipocyte hypertrophy in obese animals. The decrease in adipocyte size due to fenofibrate treatment in vivo presented in this study may be attributed to the stimulatory effects of fenofibrate on fatty acid $\beta$-oxidation through adipose PPAR $\alpha$ activation.

Fenofibrate administration to high fat diet-induced obese mice increased the expression of PPAR $\alpha$ target genes responsible for peroxisomal and mitochondrial fatty acid $\beta$-oxidation in epididymal adipose tissue. Wy14,643 also elevated the expression of mRNAs encoding PPAR $\alpha$ target enzymes 
in differentiated 3T3-L1 adipocytes. Although fibrates are known to elicit lipid catabolism by binding to PPAR $\alpha$ in liver and muscle (Ide et al., 2003; Lefebvre et al., 2006), our data indicated that fenofibrate exerts a specific regulatory effect on PPAR $\alpha$-mediated fatty acid $\beta$-oxidation in adipose tissues, leading to a reduction in adipocyte size. Our observations further showed that increases in adipose PPAR $\alpha$ target gene mRNA levels were negatively correlated with decreases in visceral fat mass and adipocyte size following fenofibrate treatment. Until recently, adipose tissues have been considered to be merely an energy storage organ. However, it has been demonstrated that increased expression of genes related to fatty acid oxidation by PPAR $\alpha$ ligands in adipose tissue of diabetic patients may contribute to improved insulin sensitivity (Boden, 2005; Bogacka et al., 2005; Jeong and Yoon, 2006), although PPAR $\alpha$ in adipose tissue is reported to have major roles in lipogenic and adipogenic activities. Similar to the lipolytic and insulin-sensitizing effects of PPAR $\alpha$ ligands in adipose tissue, PPAR $\alpha$ ligand-stimulated fatty acid oxidation in visceral adipose tissue also leads to decreased adipocyte size and improved insulin sensitivity.

Visceral fat accumulation due to adipocyte hypertrophy induces changes in the production and secretion of adipokines, such as adiponectin, visfatin, leptin, and TNF $\alpha$, involved in the development of insulin resistance (Ahima, 2006; Bulcao et al., 2006; Matsuzawa, 2006). Leptin and TNFa are overexpressed in the adipose tissues of obese, insulin-resistant rodents, which have hypertrophic adipocytes (Hotamisligil et al., 1993; Maffei et al., 1995; Okuno et al., 1998; Kralisch et al., 2007). Since leptin and TNF $\alpha$ have been reported to be at least partially responsible for insulin resistance caused by obesity (Hotamisligil et al., 1996; Ceddia et al., 1998), the decreases in leptin and TNF $\alpha$ expression may contribute to amelioration of insulin resistance. In our study, treatment of obese mice with fenofibrate decreased the mRNA levels of leptin and TNF $\alpha$, although the changes in circulating adipokine levels by fenofibrate were not measured. Thus, it seems likely that fenofibrate contributes to the improvement of insulin resistance through decreasing the expression of signaling molecules in hypertrophic adipocytes.

Adipose PPAR $\alpha$ activation by fenofibrate may contribute to lower circulating free fatty acids and triglycerides. The release of free fatty acids and triglycerides into the circulation may be decreased as a result of increased fatty acid $\beta$-oxidation in adipose tissue. Consistent with the increased adipose mRNA expression of fatty acid-metabolizing enzymes by fenofibrate treatment, circulating free fatty acids and triglycerides were decreased significantly following fenofibrate treatment in obese mice. Serum glucose and insulin levels were also decreased by fenofibrate in obese mice, which exhibited hyperinsulinemia and mild hyperglycemia. Serum insulin and glucose levels were $58 \%$ and $42 \%$ lower than those of obese mice, respectively, and these levels were comparable to the levels of lean mice. In parallel with the improvements in fasting glucose-lowering, fenofibrate reduced blood glucose levels during intraperitoneal glucose tolerance test, suggesting that fenofibrate may alleviate impaired glucose tolerance of obese mice. Given the known role of circulating free fatty acids in the inhibition of glucose uptake and utilization by muscle, our results show that fenofibrate, by reducing free fatty acids in the circulation, may contribute to the decrease in skeletal muscle insulin resistance in obese animals (Boden et al., 1994; Roden et al., 1996). Moreover, PPAR $\alpha$ agonist treatment has been reported to improve pancreatic $\beta$-cell function in insulin-resistant rodents (Koh et al., 2003; Holness et al., 2003). PPAR $\alpha$ also improves the adaptative response of the pancreatic $\beta$-cell function to pathological conditions, such as obesity (Lalloyer et al., 2006). PPAR $\alpha$ may thus be a promising target in the prevention of insulin resistance and type 2 diabetes.

In addition, much evidence obtained from human genetic studies and from rodent studies indicates that PPAR $\alpha$ plays a role in the development of obesity and adiposity although PPAR $\alpha$ is expressed at a low level in white adipose tissue. Human genetic studies have shown that a gain-of-function polymorphism L162V in the PPAR $\alpha$ gene is associated with reduced adiposity in the general population (Bosse et al., 2003). Rodent studies have also shown that larger gonadal adipose stores were reproducibly observed in PPAR $\alpha$-null mice (Akiyama et al., 2001), suggesting that PPAR $\alpha$ activator fenofibrate may be used as an inhibitor of body fat mass. However, so far, fenofibrate has not been used to control adipose tissue mass in humans maybe due to the possibility that the dose of fenofibrate for fat loss causes unwanted side effects although our present results showing that fenofibrate significantly decreased visceral fat mass in obese mice.

In conclusion, these studies demonstrate that fenofibrate treatment increases the expression of PPAR $\alpha$ target genes involved in fatty acid $\beta$-oxidation in visceral adipose tissue of obese, insulinresistant mice. These changes led to decreased adipocyte size as well as lower serum free fatty acids, adipose leptin and TNF $\alpha$ mRNA expression, thereby reducing the incidence of insulin resistance. 


\section{Methods}

\section{Animals}

For all experiments, eight-week-old mice (C57BL/6J) were housed and bred at the Korea Research Institute of Bioscience and Biotechnology under pathogen-free conditions with a standard 12-h light/dark cycle. Prior to the administration of special diets, mice were fed standard rodent chow and water ad libitum. Mice were divided randomly into three groups ( $n=5 /$ group), one of which received a low fat diet (4.5\% fat, w/w, CJ, Korea). Another group received a high fat diet containing $35 \%$ fat $(\mathrm{w} / \mathrm{w}$, Research Diets, New Brunswick, NJ), and the final group was fed the same high fat diet supplemented with fenofibrate $(0.05 \%, w / w)$ for seven weeks (Jeong et al., 2004b; Jeong and Yoon, 2007). The composition of high fat diet is shown in Supplemental Data Table S1. In all experiments, body weights were measured daily using a top-loading balance, and the person who measured the body weight was blinded to each treatment group. Animals were sacrificed by cervical dislocation, and tissues were harvested, weighed, snap-frozen in liquid nitrogen, and stored at $-80^{\circ} \mathrm{C}$ until use.

Glucose tolerance tests were performed by intraperitoneal injection (IP) of glucose (2 g/kg body weight) in mice on a high fat diet or the same high diet supplemented with fenofibrate for 7 weeks. Blood glucose were measured using a Accu-Chek Performa System (Roche, Germany) at the indicated time intervals.

\section{T3-L1 differentiation}

Mouse 3T3-L1 cells (ATCC) in 6-well plates were proliferated in DMEM containing $10 \%$ bovine calf serum (Gibco-BRL, Grand Island, NY). After cells were kept confluent for two days, they were incubated in induction medium (day 0) containing $1 \mu \mathrm{M}$ dexamethasone, $0.5 \mathrm{mM}$ 1-methyl-3-isobutyl-xanthin, and $1 \mu \mathrm{g} / \mathrm{ml}$ insulin in DMEM with $10 \%$ FBS (Gibco-BRL). The cultures were continued for two more days to induce adipocyte differentiation. Thereafter, cells were cultured in DMEM with $10 \%$ FBS for the rest of the differentiation process. All other treatments were administered on day 0 to day 2 only, and medium was changed every other day.

\section{Determination of plasma glucose, insulin, triglyceride, and free fatty acid levels}

Levels of triglycerides and glucose were measured using an automatic blood chemical analyzer (CIBA Corning, Oberlin, $\mathrm{OH}$ ). Levels of free fatty acids and insulin were measured using SICDIA NEFAZYME (Shinyang Chemical, Seoul, Korea) and a rat insulin radioimmunoassay kit (Linco, St. Charles, MO), respectively.

\section{Histological analysis}

For hematoxylin and eosin (H\&E) staining, epididymal adipose tissues were fixed in $10 \%$ phosphate-buffered formalin for one day and processed in a routine manner for paraffin sections. Five micrometer-thick sections were cut and stained with H\&E for microscopic examination. To quantitate adipocyte number and size, the H\&E-stained sections were analyzed using an image analysis system (Image Pro-Plus, Silver Spring, MD).

\section{RT-PCR}

Total cellular RNA was prepared using the Trizol reagent (Gibco-BRL, Grand Island, NY). Two $\mu \mathrm{g}$ total RNA was reverse-transcribed using Moloney murine leukemia virus reverse transcriptase and an antisense primer to generate cDNA under standard conditions. cDNA samples were amplified by PCR in a MJ Research Thermocycler (Waltham, MA). The PCR primers used for amplication are shown in Supplemental Data Table S2. The reaction consisted of 30 cycles of denaturation for $1 \mathrm{~min}$ at $94^{\circ} \mathrm{C}$, annealing for 1 min at $58^{\circ} \mathrm{C}$, and elongation for $1 \mathrm{~min}$ at $72^{\circ} \mathrm{C}$. The PCR products were analyzed by electrophoresis on a $1 \%$ agarose gel. PCR products were quantified from agarose gels using the GeneGenius kit (Syngene, Cambridge, UK).

\section{Statistical analysis}

Unless otherwise noted, all values are expressed as mean \pm SD. All data were analyzed by the unpaired, Student's $t$-test for significant differences between the mean values of each group using SigmaPlot 2001 (SPSS Inc, Chicago, IL).

\section{Supplemental data}

Supplemental Data include two tables and can be found with this article online at http://e-emm.or.kr/article/article files/SP-41-6-04.pdf.

\section{Acknowledgements}

This research was supported by Korea Research Foundation (grant No. KRF-2006-531-C00052) and Korea Science and Engineering Foundation (grant No. R01-2008000-20040-0).

\section{References}

Ahima RS. Adipose tissue as an endocrine organ. Obesity 2006;14 Suppl 5:242S-9S

Akiyama TE, Nicol CJ, Fievet C, Staels B, Ward JM, Auwerx J, Lee SS, Gonzalez FJ, Peters JM. Peroxisome proliferatoractivated receptor-alpha regulates lipid homeostasis, but is not associated with obesity: studies with congenic mouse lines. J Biol Chem 2001;276:39088-93

Boden G, Chen X, Ruiz J, White JV, Rossetti L. Mechanisms of fatty acid-induced inhibition of glucose uptake. J Clin Invest 1994;93:2438-46

Boden G. Role of fatty acids in the pathogenesis of insulin resistance and NIDDM. Diabetes 1997;46:3-10

Boden G. Free fatty acids and insulin secretion in humans. Curr Diab Rep 2005;5:167-70

Bogacka I, Xie H, Bray GA, Smith SR. Pioglitazone induces 
mitochondrial biogenesis in human subcutaneous adipose tissue in vivo. Diabetes 2005;54:1392-9

Bossé Y, Després JP, Bouchard C, Pérusse L, Vohl MC. The peroxisome proliferator-activated receptor alpha L162V mutation is associated with reduced adiposity. Obes Res 2003;11:809-16

Brun RP, Kim JB, Hu E, Spiegelman BM. Peroxisome proliferator-activated receptor gamma and the control of adipogenesis. Curr Opin Lipidol 1997;8:212-8

Brunzell JD, Hokanson JE. Dyslipidemia of central obesity and insulin resistance. Diabetes Care 1999;22:C10-C3

Bulcao C, Ferreira SR, Giuffrida FM, Ribeiro-Filho FF. The new adipose tissue and adipocytokines. Curr Diab Rep 2006;2:19-28

Cabrero A, Alegret M, Sánchez RM, Adzet T, Laguna JC Vázquez M. Bezafibrate reduces mRNA levels of adipocyte markers and increases fatty acid oxidation in primary culture of adipocytes. Diabetes 2001;50:1883-90

Ceddia RB, William WN Jr, Lima FB, Curi R. Leptin inhibits insulin-stimulated incorporation of glucose into lipids and stimulates glucose decarboxylation in isolated rat adipocytes. J Endocrinol 1998;158:R7-R9

de Souza CJ, Eckhardt M, Gagen K, Dong M, Chen W, Laurent D, Burkey BF. Effects of pioglitazone on adipose tissue remodeling within the setting of obesity and insulin resistance. Diabetes 2001;50:1863-71

Flier JS. Obesity wars: molecular progress confronts an expanding epidemic. Cell 2004;116:337-50

Holness MJ, Smith ND, Greenwood GK, Sugden MC. Acute $(24 \mathrm{~h})$ activation of peroxisome proliferator-activated receptor-alpha (PPARalpha) reverses high-fat feedinginduced insulin hypersecretion in vivo and in perifused pancreatic islets. J Endocrinol 2003;177:197-205

Hotamisligil GS, Shargill NS, Spiegelman BM. Adipose expression of tumor necrosis factor-alpha: direct role in obesity-linked insulin resistance. Science 1993;259:87-91

Hotamisligil GS, Peraldi P, Budavari A, Ellis R, White MF, Spiegelman BM. IRS-1-mediated inhibition of insulin receptor tyrosine kinase activity in TNF-alpha- and obesity-induced insulin resistance. Science 1996;271:665-8

Ide T, Shimano H, Yoshikawa T, Yahagi N, Amemiya-Kudo M, Matsuzaka T, Nakakuki M, Yatoh S, lizuka Y, Tomita S Ohashi K, Takahashi A, Sone H, Gotoda T, Osuga J, Ishibashi $S$, Yamada N. Cross-talk between peroxisome proliferatoractivated receptor (PPAR) alpha and liver X receptor (LXR) in nutritional regulation of fatty acid metabolism. II. LXRs suppress lipid degradation gene promoters through inhibition of PPAR signaling. Mol Endocrinol 2003;17: $1255-67$

Jensen MD. Is visceral fat involved in the pathogenesis of the metabolic syndrome? Human model. Obesity (Silver Spring) 2006;14:20S-4S

Jeong S, Han M, Lee H, Kim M, Nicol CJ, Kim BH, Choi JH, Oh GT, Yoon M. Effects of fenofibrate on high fat diet-induced body weight gain and adiposity in female? C57BL/6J mice. Metabolism 2004a;53:1284-9
Jeong S, Kim M, Han M, Lee H, Ahn J, Kim M, Song YH, Shin C, Nam KH, Kim TW, Oh GT, Yoon M. Fenofibrate prevents obesity and hypertriglyceridemia in LDL receptor-null mice. Metabolism 2004b;53:607-13

Jeong S, Yoon M. Troglitazone lowers serum triglycerides with sexual dimorphism in C57BL/6J mice. J Exp Biomed Sci 2006;12:65-72

Jeong S, Yoon M. Inhibition of the actions of peroxisome proliferator-activated receptor $\alpha$ on obesity by estrogen. Obesity 2007:15:1430-40

Kadowaki T. Insights into insulin resistance and type 2 diabetes from knockout mouse models. J Clin Invest 2000;106:459-65

Kissebah AH. Central obesity: measurement and metabolic effects. Diabetes Rev 1997;5:8-20

Kliewer SA, Lehmann JM, Wilson TM. Orphan nuclear receptors: shifting endocrinology into reverse. Science 1999;284:757-60

Koh EH, Kim MS, Park JY, Kim HS, Youn JY, Park HS, Youn $\mathrm{JH}$, Lee KU. Peroxisome proliferator-activated receptor (PPAR)-alpha activation prevents diabetes in OLETF rats: comparison with PPAR-gamma activation. Diabetes 2003; $52: 2331-7$

Kralisch S, Sommer G, Deckert CM, Linke A, Bluher M, Stumvoll M, Fasshauer M. Adipokines in diabetes and cardiovascular diseases. Minerva Endocrinol 2007;32: 161-71

Kubota N, Terauchi Y, Miki H, Tamemoto H, Yamauchi T, Komeda K, Satoh S, Nakano R, Ishii C, Sugiyama T, Eto K, Tsubamoto Y, Okuno A, Murakami K, Sekihara H, Hasegawa G, Naito M, Toyoshima Y, Tanaka S, Shiota K, Kitamura T, Fujita T, Ezaki O, Aizawa S, Kadowaki T, et al. PPAR gamma mediates high-fat diet-induced adipocyte hypertrophy and insulin resistance. Mol Cell 1999;4:597-609

Lalloyer F, Vandewalle B, Percevault F, Torpier G, Kerr-Conte J, Oosterveer M, Paumelle R, Fruchart JC, Kuipers F, Pattou F, Fiévet C, Staels B. Peroxisome proliferator-activated receptor alpha improves pancreatic adaptation to insulin resistance in obese mice and reduces lipotoxicity in human islets. Diabetes 2006;55:1605-13

Lefebvre P, Chinetti G, Fruchart JC, Staels B. Sorting out the roles of PPAR alpha in energy metabolism and vascular homeostasis. J Clin Invest 2006;116:571-80

Maffei M, Fei H, Lee GH, Dani C, Leroy P, Zhang Y, Proenca R, Negrel R, Ailhaud G, Friedman JM. Increased expression in adipocytes of ob RNA in mice with lesions of the hypothalamus and with mutations at the db locus. Proc Nat Acad Sci USA 1995;92:6957-60

Matsuzawa $Y$. The metabolic syndrome and adipocytokines. FEBS Lett 2006;580:2917-21

Murphy JE, Zhou S, Giese K, Williams LT, Escobedo JA, Dwarki VJ. Long-term correction of obesity and diabetes in genetically obese mice by a single intramuscular injection of recombinant adeno-associated virus encoding mouse leptin. Proc Natl Acad Sci USA 1997;94:13921-6

Okamoto $Y$, Higashiyama $H$, Inoue $H$, Kanematsu $M$, 
Kinoshita M, Asano S. Quantitative image analysis in adipose tissue using an automated image analysis system: differential effects of peroxisome proliferator-activated receptor-alpha and -gamma agonist on white and brown adipose tissue morphology in AKR obese and $\mathrm{db} / \mathrm{db}$ diabetic mice. Pathol Int 2007;57:369-77

Okuno A, Tamemoto H, Tobe K, Ueki K, Mori Y, Iwamoto K, Umesono K, Akanuma Y, Fujiwara T, Horikoshi H, Yazaki Y, Kadowaki T. Troglitazone increases the number of small adipocytes without the change of white adipose tissue mass in obese Zucker rats. J Clin Invest 1998;101:1354-61

Roden M, Price TB, Perseghin G, Petersen KF, Rothman DL, Cline GW, Shulman GI. Mechanism of free fatty acid-induced insulin resistance in humans. J Clin Invest 1996;97: 2859-65

Schoonjans K, Staels B, Auwerx J. Role of the peroxisome proliferator-activated receptor (PPAR) in mediating the effects of fibrates and fatty acids on gene expression. J Lipid Res 1996;37:907-25

Spiegelman BM, Flier JS. Adipogenesis and obesity: rounding out the big picture. Cell 1996;87:377-89

Staels B, Dallongeville J, Auwerx J, Schoonjans K, Leiters- dorf E, Fruchart JC. Mechanism of action of fibrates on lipid and lipoprotein metabolism. Circulation 1998;98:2088-93

Taylor SI, Barr V, M. Reitman M. Does leptin contribute to diabetes caused by obesity? Science 1996;274:1151-2

Vazquez M, Roglans N, Cabrero A, Rodríguez C, Adzet T, Alegret M, Sanchez RM, Laguna JC. Bezafibrate induces acyl-CoA oxidase mRNA levels and fatty acid peroxisomal beta-oxidation in rat white adipose tissue. Mol Cell Biochem 2001;216:71-8

Wellen KE, Hotamisligil GS. Inflammation, stress, and diabetes. J Clin Invest 2005;115:1111-9

Wickelgren I. Obesity: how big a problem? Science 1998; 280:1364-7

Yoon M, Jeong S, Nicol CJ, Lee H, Han M, Kim JJ, Seo YJ, Ryu C, Oh GT. Fenofibrate regulates obesity and lipid metabolism with sexual dimorphism. Exp Mol Med 2002; 34:481-8

Yoon M, Jeong S, Lee H, Han M, Kang JH, Kim EY, Kim M, Oh GT. Fenofibrate improves lipid metabolism and obesity in ovariectomized LDL receptor-null mice. Biochem Biophys Res Commun 2003;302:29-34 